\title{
Responsible Resource Management in Remanufacturing-Framework for Qualitative Assessment in Small and Medium-Sized Enterprises
}

\author{
Paulina Golinska-Dawson *(D), Karolina Werner-Lewandowska (D) and Monika Kosacka-Olejnik (D) \\ Faculty of Engineering Management, Poznan University of Technology, 60-965 Poznan, Poland; \\ karolina.werner@put.poznan.pl (K.W.-L.); monika.kosacka@put.poznan.pl (M.K.-O.) \\ * Correspondence: paulina.golinska@put.poznan.pl; Tel.: +48-61-665-3401
}

\section{check for}

updates

Citation: Golinska-Dawson, P.; Werner-Lewandowska, K.;

Kosacka-Olejnik, M. Responsible

Resource Management in

Remanufacturing-Framework for

Qualitative Assessment in Small and Medium-Sized Enterprises. Resources 2021, 10, 19. https://doi.org/

$10.3390 /$ resources 10020019

Academic Editors: Sebastian Kot and Robert Stefko

Received: 5 January 2021

Accepted: 18 February 2021

Published: 23 February 2021

Publisher's Note: MDPI stays neutral with regard to jurisdictional claims in published maps and institutional affiliations.

Copyright: (c) 2021 by the authors. Licensee MDPI, Basel, Switzerland. This article is an open access article distributed under the terms and conditions of the Creative Commons Attribution (CC BY) license (https:// creativecommons.org/licenses/by/ $4.0 /)$.

\begin{abstract}
Through the remanufacturing process, obsolete, broken, and end-of-use products are brought to "a like new condition". Remanufacturing is an example of implementation of circular economy at a company level. There are few studies on responsible resource management in a remanufacturing process. This paper contributes to this research gap by presenting a two-layered framework, which uses the maturity model theory, and it allows for a quick scan of a remanufacturing process. First, in the descriptive layer of the framework we define five maturity levels with regard to responsible resource management. We analyze water, emissions, energy, and materials, and describe relevant responsible resource management practices, which we link with maturity levels. We also design the relevant self-assessment tool which utilizes the existing expert's knowledge of a company. Then, in the prescriptive layer of the framework, we propose a method for the identification of the maturity gap, and areas for improvement. We develop a procedure for prioritizing the measures, which shall be implemented in order to achieve a higher level of responsible resource management in a remanufacturing company. The framework is tested in small and medium-sized enterprises from the automotive industry.
\end{abstract}

Keywords: resource-efficient remanufacturing; quick scan method; environmental sustainability; maturity model; resources

\section{Introduction}

\subsection{Motivation for this Study}

The depletion of natural resources and the burdens resulting from climate change have triggered the need to decouple the economic growth from the consumption of natural resources [1]. The circular economy (CE) concept provides a new alternative to the long lasting paradigm of the linear economy model (take-make-use-dispose). It has gained much attention in academia in the last decade [2]. The primary goal of circular economy is "to transform business processes into sustainable, closed-loop resource systems" ([3], p. 2). The circular economy concept aims for redesigning the industrial practices in order to establish more resource-efficient business models that allow reducing, reusing, and recycling.

Implementing the principles of Circular Economy at micro-level (e.g., a company) is challenging [4]. At the same time, companies (as the singular actor) own most resources and capabilities, and thus can stimulate CE transition [5]. In companies, the focus shall be placed on achieving the circular flow of materials and energy in industrial processes and avoiding resource leaks [6].

In that context, responsible resource management in a company is defined here, as the implementation of the management practices, which focus on increasing the resource efficiency and allow for the resource conservation by closing materials, water, and energy loops. 
The resource efficiency approach derives from the 'eco-efficiency' view, and it aims for reducing consumption of resources, reducing the impact on nature, and increasing the value of used resources [7]. However, the resource efficiency approach presumes that resources are infinite. In the $\mathrm{CE}$, the resource efficiency concept is extended by the pledge for resource conservation that allows a company to be economically viable and environmentally sustainable [8]. The resource conservation aims for the restoring of energy, materials, and value added with waste prevention [9].

Hence, responsible resource management is pivotal to fulfill the Goal 12 UN SDG "Responsible consumption and production", as it includes the targets on sustainable management and efficient use of natural resources (Target 12.2) and on the reduction of waste generation through prevention, reduction, recycling, and reuse (Target 12.5) [10].

Small and medium-sized enterprises (SMEs) are a crucial link at micro-level towards CE transition at meso and macro-levels. In 2018, in the EU there were 25.1 million small and medium-sized enterprises [11], with the vast majority of micro-sized (max. 9 employees), 1.47 million small enterprises (10 and 49 employees), and 236 thousand medium-sized (50 to 249 employees). At the same time, SMEs are often characterized by low resource efficiency [12]. Moreover, they also have limited technological, financial, and organizational capabilities, which reduce their abilities to implement sophisticated methods for the quantitative environmental impact assessment, as life cycle assessment or lifecycle costing $[13,14]$. SMEs rely on ad hoc solutions and expert's knowledge, processes suffer from low standardization, and the corporate reporting standards are rarely used [15]. SMEs have a limited number of staff and often limited access to financial means, thus there are required methods and models that respond to their specific needs, and are easy to implement [16].

In this paper, we focus in particular on the SMEs in the remanufacturing sector. Remanufacturing is an example of a business practice that implements the CE guidelines at a company level. Remanufacturing is an industrial process that allows for bringing back core (non-functional, discarded or trade-in products) to its original performance specifications, or to upgrade it to a new specifications [17]. In the literature, we can find proofs that remanufacturing is the most resource efficient recovery option for endof-use products [18-20]. However, the SMEs in the remanufacturing sector suffer from low resource-efficiency [14,21]. Responsible resource management in remanufacturing encompasses actions, as follows:

- Economically efficient use of resources,

- reduction of waste and emissions generation,

- maximization of the recovery rate and use of secondary materials.

\subsection{Aim of this Paper, its Originality, and Main Contributions}

In this paper, we aim to develop a decision making framework for responsible resource management in remanufacturing (so called RRMRem). The framework shall provide decision makers with actionable knowledge on the current state (as-is state) with regard to responsible resource management practices. Further, it shall allow for identifying the inefficiencies in resource management practices and proposing the improvement actions.

Our previous studies in the remanufacturing sector $[14,21]$ have shown that SMEs there face difficulties in implementing advanced quantitative methods.

The qualitative methods allow for simplified, linguistic assessment by applying the in-house expert's knowledge. They allow identifying the current stage (as-is) even when numerical data is not collected or available from external sources.

Previous studies $[14,15,22,23]$ have explored the maturity model (MM) with regard to its potential, as a framework for sustainability related assessment in a company. Bititci et al. [24] have defined the maturity model as a "matrix of practices that defines, for each organizational area, the level of formality, sophistication, and embeddedness of practices from ad hoc to optimizing". Pullen [25] states that the maturity model is "a structured collec- 
tion of elements that describe the characteristics of effective processes at different stages of development".

The advantage of the maturity model is its simplicity in application and evolutionary character, as it provides a sequential description of the requirements, and practices at each level, and therefore it gradually guides the company on how to achieve excellence in the analyzed domain [23]. The importance of the evolutionary approach in SMEs has been addressed by Veleva and Ellenbecker [26] " ( . . ) organizations need to begin with simple, easy to implement measures of compliance and resource efficiency and move toward more complex indicators, addressing environmental and social effects, supply chain and life-cycle impacts."

The maturity model can be elaborated on the market-based view or on the resourcebased view [27]. In this paper, the resource-based view is applied. The maturity models are relevant for the improvement of the economic and ecological performance, as they provide tools and techniques for dealing with complexity and highlight the potential for improvements [22,28]. Correira et al. [22] have conducted a systematic literature review on maturity models in the sustainability domain and they have concluded that the majority of research provides a descriptive, usually linguistics assessment of the current state, but the prescriptive power is limited. That limitation results from lack of an application framework (prescriptive layer).

Authors have found only one maturity model, which is solely dedicated for an assessment of the remanufacturing process, namely "The Remanufacturing Process Capability Maturity Model" (RPCMM) [29]. The RPCMM allows for the assessment of current resource-efficiency (as-is), but it has a very limited descriptive power. It does not provide tools and methods for identifying the source of inefficiencies, and implementing improvement actions in a company.

The main goal of this paper is to develop the decision making framework for responsible resource management for remanufacturing SMEs (RRMRem), that is based on the maturity model theory. The framework shall guide the decision-maker toward transition from the current state (as-is state) to a desirable future state of responsible resource management (to-be). The RRMRem has the descriptive power, as it includes the definition of the maturity levels and tool for current state assessment (RRMQ-responsible resource management questionnaire). Moreover, it provides an application framework, which allows a company to make necessary changes in the current business practices to progress toward a higher maturity level (to-be state).

The originality of the proposed framework results from relating the maturity level (current state) with appropriate improvement's actions, and providing guidance to a decision-maker through improvement path toward more responsible resource management in remanufacturing. The main contributions of this paper are:

- A definition of the maturity levels for responsible resource management in a SME;

- a design of the responsible resource management practices (RRMP) that are relevant for each maturity level in a SME (measured with responsible resource management questionnaire RRMQ);

- a proposal of an integrated indicator OWEEM (Overall Water, Emissions, Energy, Materials), which allows for classifying a company in a synthetic way to relevant maturity level;

- a method for identification of the maturity's gaps and prioritizing the improvement's actions, which are necessary to progress towards a higher maturity level.

The paper is organized as follows: First the background and motivation of this study are presented (Section 1). In Section 2, the methodology is described, as well as the proposed framework with relevant tools and methods. In Section 3, the empirical testing of the framework (RRMRem) is provided. The discussion on the results is presented in Section 4. The final conclusions, benefits and limitations of this study, and further research are discussed in Section 5. 


\section{Materials and Methods}

\subsection{Research Design}

The maturity models in the domain of sustainability are usually enrooted in empirical research strategies (e.g., case study), as they allow for the exploration of the research domain even in an infancy stage. The advantages of the MM can be summarized, as follows [22,23]:

- A descriptive tool for evaluation of company strengths and weaknesses,

- a prescriptive instrument for performance improvement,

- a comparative tool for evaluation of processes across companies and further comparison with standards and best practices.

The MMs are suitable for application in SMEs, as they enable internal or external benchmarking and can act as reference models [30]. Additionally, they can be applied for current state analysis, and they might facilitate positive transformation towards a desirable future state (to-be). Tarhan et al. [31] in systematic literature have analyzed over 60 business process maturity models and identified further research needs, as follows:

- Development of MMs with regard to their prescriptive properties,

- extended empirical validation of MMs to prove their utilitarian function,

- detachment of the assessment methods from model's description (separate descriptive and prescriptive layers).

In order to contribute to the existing research gap the research questions are stated, as follows:

- $\quad$ RQ1: How can the responsible resource management practices be evaluated in a SME based on the existing in-house expert's knowledge?

- RQ2: How can the current management practices be improved in order to facilitate transformation towards responsible resource management in a SME?

The main stages for development of the proposed framework are presented in Figure 1.

The authors have used a multimethod approach in order to find the answers to the stated research questions. This study applies methods as follows: Critical literature review, questionnaire-based interviews in a company, case studies, indicators analyses, and benchmarking.

After each stage from Figure 1, the research team performed evaluation of the outcomes during internal team meetings. The theoretical outcomes were triangulated between team members. The draft version of the assessment tool (so-called responsible resource management questionnaire RRMQ) was consulted with the industrial partners (remanufacturing companies). Their feedback was incorporated into the final version of the tool (Supplementary Material).

The final version of the designed decision framework includes:

- A descriptive layer, with: A definition of the maturity levels, and a description of the responsible resource management practices (RRMPs) in the assessment tool (RRMQ).

- A prescriptive layer, with: An indicator-based method for assessment and classification of the maturity level, and a benchmarking method for identifying the appropriate actions that should be taken to order to improve the current situation.

The detailed description of each element of the framework is provided in the next section.

\subsection{The Framework for Responsible Resource Management in Remanufacturing RRMRem-Structure, Methods, and Tools}

The developed framework is rooted in the previous authors' work [14,15]. The pragmatic approach is implemented, as previously conducted case studies among groups of SMEs have indicated, that there is a need for an qualitative approach, which is based on expert's knowledge. The framework aims to provide the decision-makers with actionable knowledge on the current state of resource management practices and guide then through the improvement process. 


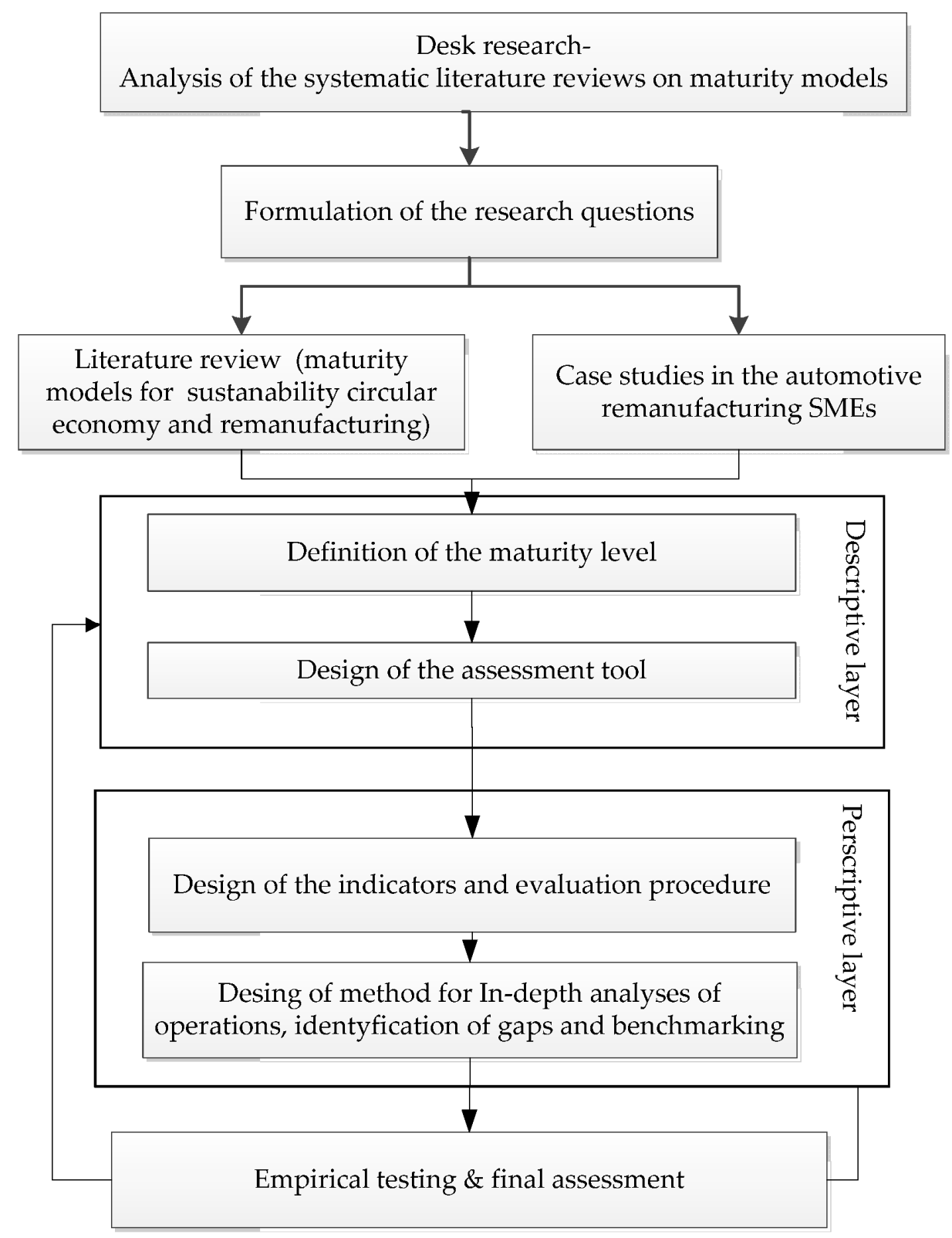

Figure 1. Development of the responsible resource management in remanufacturing (RRMRem) framework.

The maturity of the responsible resource management practices is defined here, as an extent to which resources are identified, controlled, and optimized with regards to their responsible management.

First, based on the literature review and multiple case studies the maturity levels are defined as follows:

- $\quad$ Level ML1 (very low)—the responsible resource management practices in the remanufacturing process are not applied or are applied incompletely by a company.

- Level ML2 (low) - the responsible resource management practices in the remanufacturing process are applied ad hoc (e.g., to solve a current problem or to comply with specific customer requirements/legal requirements) in a company, and processes are not formalized.

- Level ML3 (medium) — the responsible resource management practices are formalized, measured at facility, and ad hoc actions are taken. 
- Level ML4 (high) — the responsible resource management practices are formalized, measured, and controlled at each stage of the process/each work station on a regular basis, and improvement actions are taken.

- Level ML5 (very high) — the responsible resource management practices are formalized, measured, and controlled at each stage of the process/each work station on a regular basis, and improvement actions are taken for continuous optimization.

In the proposed framework, ML5 is a reference level for responsible resource management in remanufacturing at SMEs.

The remanufacturing process aims to transform a core (used/obsolete product) into a remanufactured product for use in multiple cycles or to cannibalize poor quality core for reuse purpose, as spare parts and secondary material. The remanufacturing SME is analyzed through simplified framework, with focus on:

- I = Inputs (water, primary and secondary materials, energy consumption),

- $\quad$ outputs (emissions, sludge, waste), and

- value added in remanufacturing (energy saving, recycling, and increased material recovery).

The descriptive layer is presented in Figure 2.

Resources group
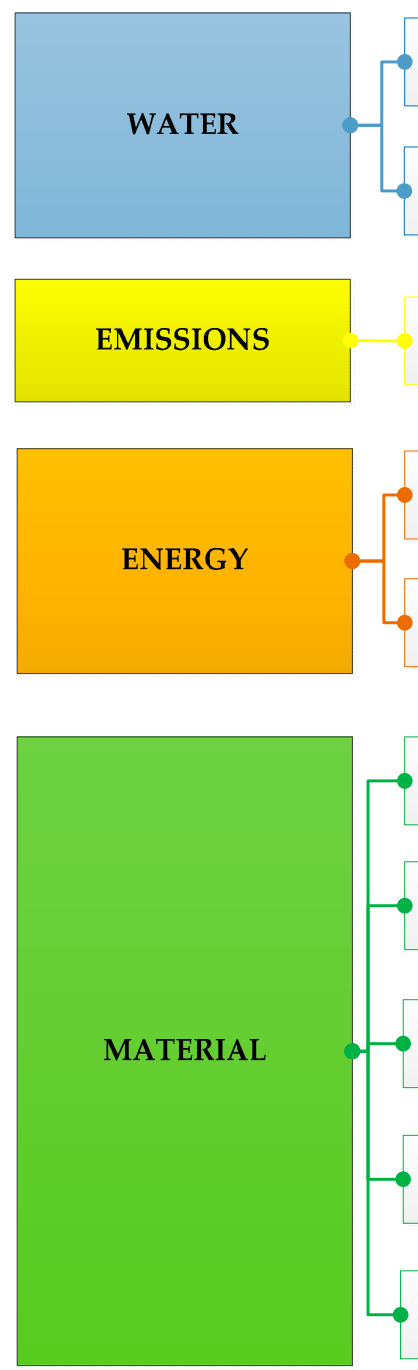

Criteria

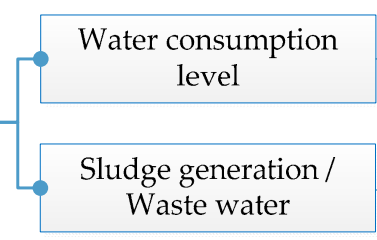

GHG Emissions level

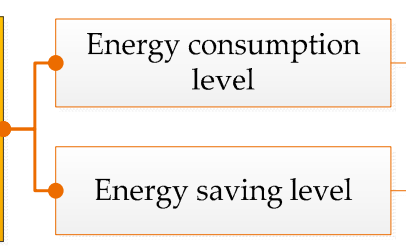

Primary materials consumption level

Material recovery level

Process waste generation level

\section{Recycling level}

Reused/recycled materials consumption

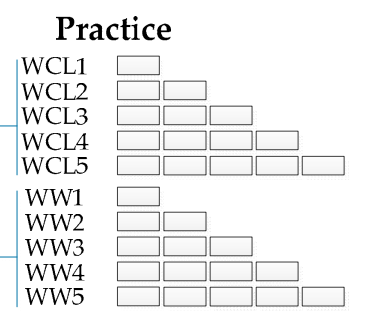

WW

GEL1

GEL2

GEL3

GEL4

ECL1

ECL2

ECL4

ESL1

ESL1
ESL2

ESL3

ESL4

MCL1

MCL2

MCL2

MCL3

MCL5

MRL1

MRL2

MRL3

MRL4

MRL5

WGL1

WGL3

WGL4

WGL5

RL1

RL2

RL3

RL5

RMC1

RMC2

RMC3

RMC4

RMC5
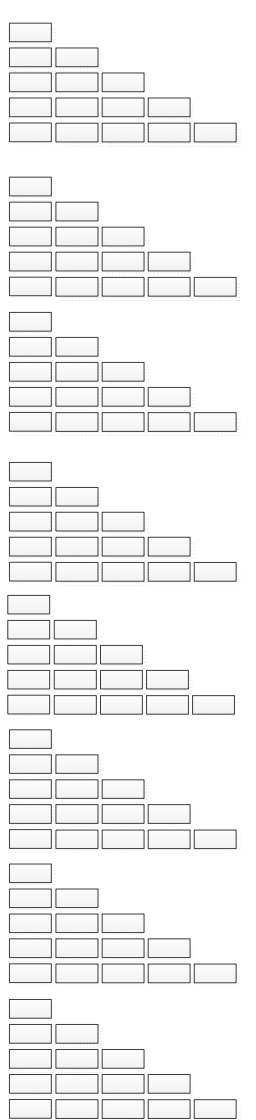

Figure 2. The descriptive layer structure. 
In order to assess the current maturity level with regard to responsible resource management, we propose the tool (RRMQ) with the Likert-scale. It allows for self-assessment of existing resource management practices in a company using expert's knowledge. A similar approach has also been recommended by [22]. The questionnaire (RRMQ) describes management practices which correspond to each maturity level. The questions' order is consistent with the structure of the descriptive layer, as presented in Figure 2. In the descriptive layer, there are 4 aggregated categories (Water, Emissions, Energy, Materials), 10 criteria for assessment, and 50 relevant responsible resource management practices (RRMPs). The RRMPs are described for each criterion in accordance with each maturity level. They are designed based on 4 in-depth case studies conducted by the authors in remanufacturing SMEs, and additional data from interviews with industrial and academic experts. The empirical data has been triangulated with the characteristics of remanufacturing SMEs extracted from other case studies found during the literature review. Table 1 presents an example of the RRMPs. The full description of the 50 management practices is provided in Supplementary Material. All the RRMPs are transposed to the assessment tool (RRMQ). The descriptive phase of the assessment is concluded with the graphic presentation of the maturity profile. The profile reflects the expert's knowledge based self-assessment using the RRMQ tool (see Supplementary Material). The maturity profile presents the current state of practices (as-is) in a company with regard to their responsible (or not) resource management.

The prescriptive layer of the proposed framework aims to provide guidelines for a SME on how to progress towards a higher maturity level. The prescriptive layer consists of:

- An indicator-based assessment method, and

- a benchmarking method in order to identify maturity gaps and prioritize necessary improvement's actions.

The logic of the prescriptive layer is presented in Figure 3.

The indicator-based assessment allows for translating the yes/no answers for each criterion from the assessment tool RRMQ (linguistic binary expert's assessment) into the value of an integrated indicator, called OWEEM (Overall Water-Emissions-Energy-Materials). OWEEM is rooted in the "green \& lean" approach [32], where lean management methods and tools are used in order to eliminate wasteful practices in a company, and therefore achieve more efficient use of resources and reduction of waste in the remanufacturing process. The OWEEM is an aggregated indictor, and it is calculated per analogy to wellknown lean management OEE indicator (overall equipment effectiveness). The OEE allows for assessing the process and identifying the losses. In this paper, the proposed OWEEM indicator is calculated as follows (Equation (1)):

$$
\mathrm{OWEEM}=R G_{W} \times R G_{E M} \times R G_{E} \times R G_{M}
$$

where:

$R G_{W}$ - is the aggregated score for category Water,

$R G_{E M}$ - is the aggregated score for each category Emissions,

$R G_{E}$-is the aggregated score for each category Energy,

$R G_{M}$ - is the aggregated score for category Material.

The aggregated score is calculated for each category separately as follows (Equation (2)):

$$
R G_{C i}=\frac{R M M Q_{R G C i}}{\left(s_{R G j}\right)_{\max } \times\left(w_{R G j}\right)_{\max }} \times 100 \%
$$

where:

$R M M Q_{R G C i}$ is the score from responsible resource management questionnaire for the analyzed category,

$S_{R G j}$ is the scoring for criterion " $j$ " in the analyzed category and $S_{R G j}=\{0,1\}$,

$W_{R G j}$ is the weight $w_{R G j} \in\langle 1,5\rangle$ and $w_{R G j} \in Z$. 
$R M M Q_{R G}$, is calculated as follows (Equation (3)):

$$
R M M Q_{R G C i}=\sum_{j=1}^{5} s_{R G j} \times w_{R G j}
$$

Table 1. An example of the responsible resource management practices' description.

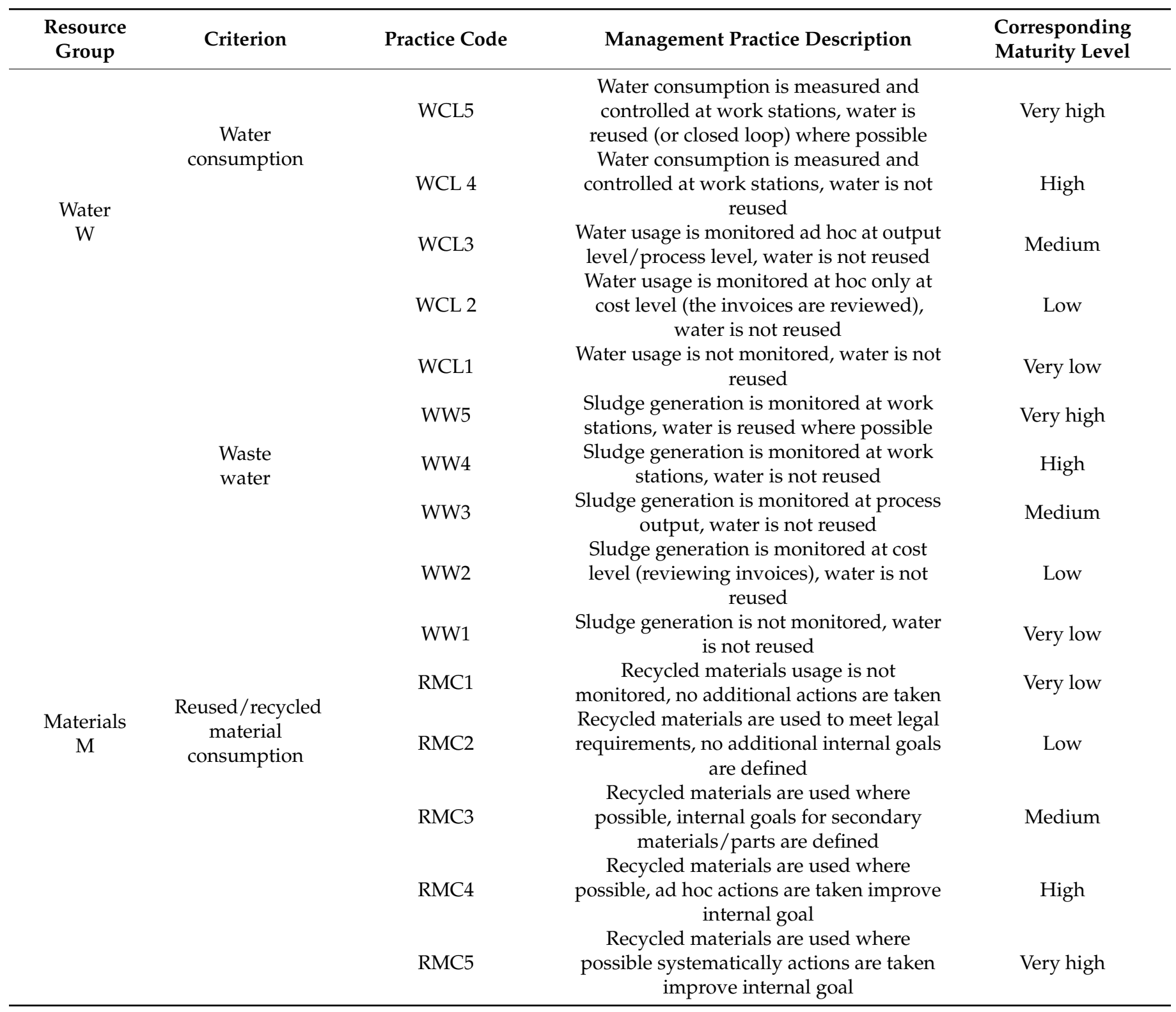

In Equation (2), value of denominator of the fraction is taken as a benchmark level. In this way, the degree of compliance is calculated in each resource group (steps from 2.1 to 2.4 on Figure 3). Finally, based on the value of OWEEM, a company is classified into a relevant maturity level from ML1 to ML5. The classification rule is presented in Table 2.

The benefit of the proposed solution is its flexibility, as the amount of criteria in each category can be extended or reduced for a particular company, without influencing the complexity of OWEEM calculation.

The next step in the decision framework is application of the benchmarking method, in order to identify maturity gaps, and to prioritize a necessary improvement's actions. The maturity level ML5 is a benchmark, as it represents the reference state of responsible resource management. The maturity gap is calculated for each category (Water, Emissions, 
Energy, and Materials). Then priorities are given accordingly to the size of the maturity gap in descending order (the bigger the gap, the higher the priority to take improvement actions). The maturity gap (Mgap $\mathrm{RGCi}_{\text {) }}$ ) is calculated as follows (Equation (4)):

$\operatorname{Mgap}_{\mathrm{RGCi}}=1-\mathrm{RG}_{\mathrm{Ci}}$

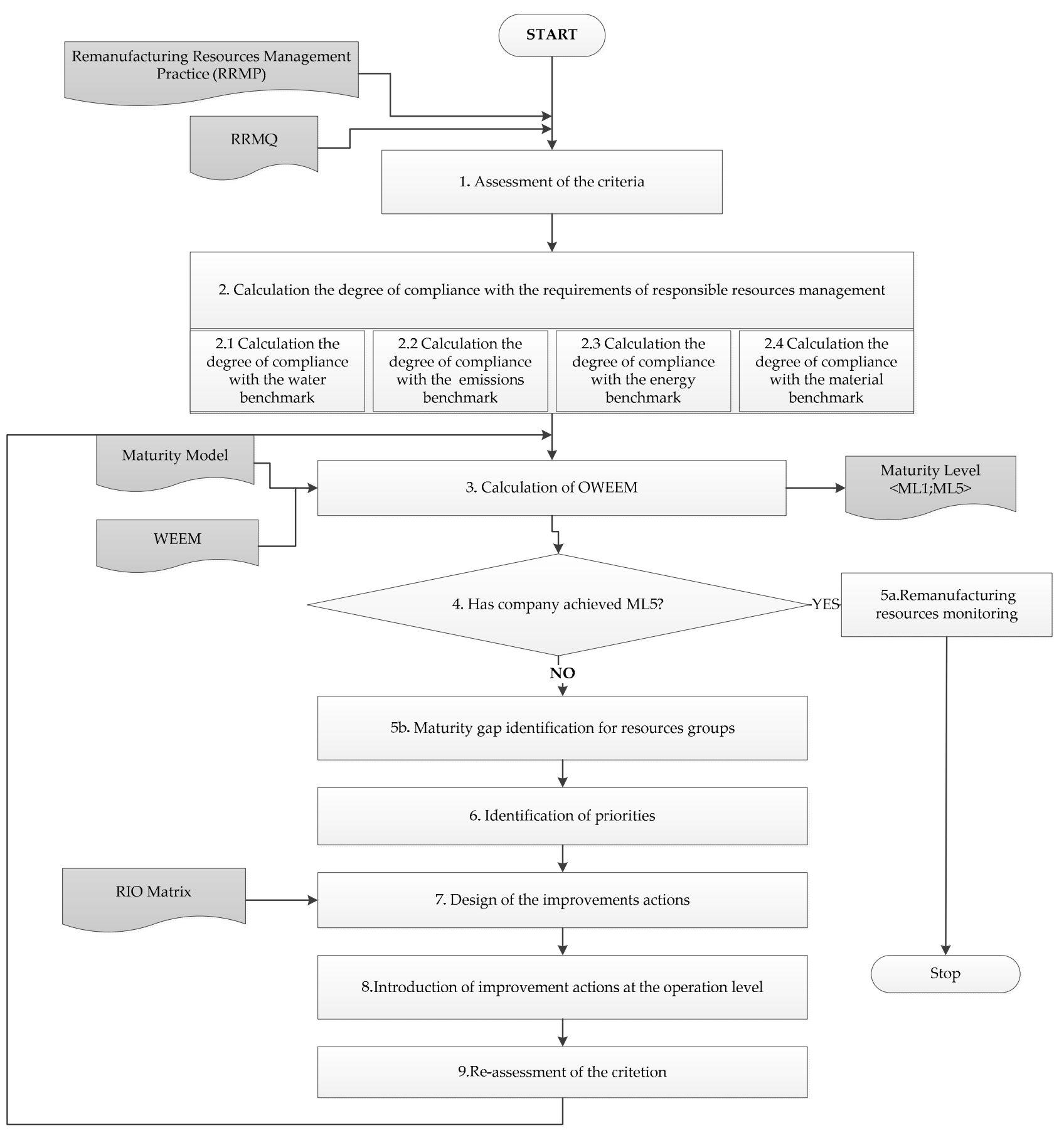

Figure 3. Logic of the prescriptive layer of RRMRem. 
Table 2. Maturity level—-the classification rules. OWEEM: Overall Water-Emissions-Energy-Materials.

\begin{tabular}{|c|c|c|c|}
\hline & OWEEM Score & & Maturity Level \\
\hline \multirow{5}{*}{ IF } & $<3 \%$ & \multirow{5}{*}{ THEN } & ML1 \\
\hline & $<3 \%, 13)$ & & ML2 \\
\hline & $<13 \%, 41)$ & & ML3 \\
\hline & $<41 \%, 100)$ & & ML4 \\
\hline & $100 \%$ & & ML5 \\
\hline
\end{tabular}

The improvement's actions are designed based on:

- RIO Matrix (Resource's Importance in Operations),

- the management practices (RRMPs) from the next maturity level $\mathrm{ML}_{(\mathrm{i}+1)}$,

- priority $\operatorname{Pr}_{\mathrm{Ci}}$ for the resource's group.

For example, if an analyzed company is currently at very low maturity level ML1 (according to the calculated OWEEM value), then the management practices (RRMPs) are applied from next level ML2. The RIO Matrix is a simple tool which uses expert's knowledge, and it enables the identification of the key resources at the operations level. After the improvement's actions are implemented at a company, the value of the maturity gap should be recalculated to verify if the company has progressed towards more responsible resource management. The next section presents the empirical testing of the proposed decision making framework in SMEs from the remanufacturing sector.

\section{Results}

Testing Approach

The framework was tested in two phases. First, the descriptive layer was applied to four real-life case studies. The aim was to identify the potential problems with the design of the assessment questionnaire and description of the responsible management practices in the context of the maturity levels. The four companies have characteristics, as follows:

- Company A is a small-sized company (below 50 employees), it remanufactures alternators, pumps, and starters. The company operates at one facility. It is an independent remanufacturer (IR).

- Company B is a medium-sized company, it remanufactures alternators and starters. The company operates at one facility, in a mixed model, as it remanufactures under own brand, and as a service provider for bigger automotive original parts suppliers.

- Company $\mathrm{C}$ is a small-sized company, it provides remanufacturing services of engines for transport companies.

- Company D is a small-sized company, it offers remanufacturing services of Diesel particulate filter (DPF) for individuals and companies.

For each company, one expert filled in the questionnaire (RRMQ from Supplementary Material) in order to self-assess the current state of responsible resource management in the company. Each expert has got at least 5 years of experience in automotive remanufacturing. The experts have declared that they have sufficient knowledge regarding the resources of a company, and the existing resource management practices. The experts completed the questionnaire (RRMQ) in times varying from $5 \mathrm{~min}$ to $11 \mathrm{~min}$. They gave yes/no answers with regard to the appearance of each management practice. Only one most relevant answer (yes) was allowed for each criterion. Based on the answers from the questionnaire, the members of the research team calculated the cumulative score and classified a company to the corresponding maturity level from ML1 (very low) to ML5 (very high). The calculation and classification procedure was double-checked by at least one more team member. The results are presented in Table 3. 
Table 3. The results of case studies.

\begin{tabular}{|c|c|c|}
\hline Company & Testing Summary & Maturity Level \\
\hline A & $\begin{array}{l}\text { Application of the descriptive framework is } \\
\text { feasible, the assessment with responsible } \\
\text { resource management questionnaire (RRMQ) } \\
\text { took approximately } 8 \text { min. }\end{array}$ & $\begin{array}{l}\text { Company is at low maturity } \\
\text { level (ML 2) }\end{array}$ \\
\hline B & $\begin{array}{l}\text { Application of the descriptive framework is } \\
\text { feasible, the assessment with RRMQ took } \\
\text { approximately } 6 \text { min. Expert has declared that } \\
\text { the tool is easy to use, the criteria and description } \\
\text { of the management practices are relevant. }\end{array}$ & $\begin{array}{l}\text { Company is at medium } \\
\text { maturity level (ML 3) }\end{array}$ \\
\hline C & $\begin{array}{l}\text { Application of the descriptive framework is } \\
\text { feasible, the assessment with RRMQ took } \\
\text { approximately } 11 \text { min. Expert has declared that } \\
\text { the tool is easy to use, and the description of the } \\
\text { management practices is suitable. }\end{array}$ & $\begin{array}{l}\text { Company is at very low } \\
\text { maturity level (ML 1) }\end{array}$ \\
\hline $\mathrm{D}$ & $\begin{array}{l}\text { Application of the descriptive framework is } \\
\text { feasible, the assessment with RRMQ took } \\
\text { approximately } 5 \text { min. Expert has declared that } \\
\text { the tool is easy to use and the management } \\
\text { practices are well defined. }\end{array}$ & $\begin{array}{l}\text { Company is at very low } \\
\text { maturity level (ML 1) }\end{array}$ \\
\hline
\end{tabular}

Afterwards, the prescriptive layer was tested by an in-depth case study in Company D. Company D was chosen because, during the first stage of empirical testing, it was assessed at a very low maturity level (ML1) with regard to responsible resource management practices. The testing was performed in accordance with the method presented in Figure 3. The results from the expert's assessment (from RRMQ) were aggregated in accordance with Equation (3) for each category: Water, Emissions, Energy, and Materials, and presented in the form of the maturity's profile in Figure 4. The values in Figure 4 were calculated in accordance with Equation (2), and they showed to what extend the company was applying the responsible management practices in each category.

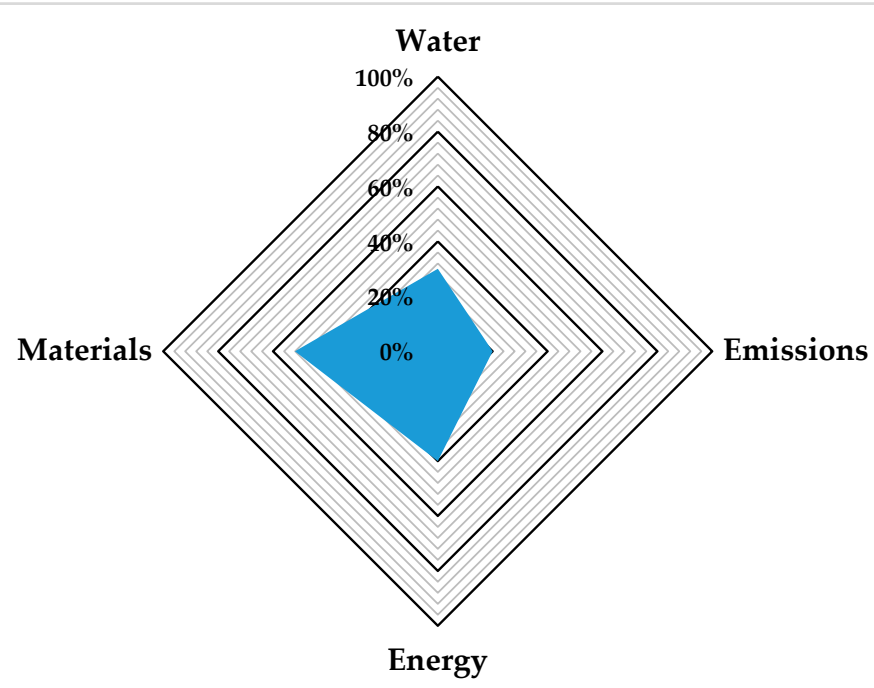

Figure 4. Maturity profile of Company D.

After the value of the OWEEM was calculated, the maturity gap was indicated for each category (Water, Emission, Energy, and Materials) in order to assign the priorities for the further improvement's actions. In Table 4 presents the values, which have been calculated using the equations from the previous section (Equations (1)-(4)). 
Table 4. Current state analysis (as-is) in Company D.

\begin{tabular}{cccccc}
\hline $\begin{array}{c}\text { Category } \\
\mathbf{R G}_{\mathbf{C i}}\end{array}$ & $\begin{array}{c}\text { RRMQ } \\
\text { Score } \\
\text { (Equation (3)) }\end{array}$ & $\begin{array}{c}\text { Maturity Gap } \\
\text { Mgap }\end{array}$ & $\begin{array}{c}\text { Prionity } \\
\text { (Equation (4)) }\end{array}$ & $\begin{array}{c}\text { OWEEM } \\
\operatorname{Pr}_{\text {RGCi }}\end{array}$ & $\begin{array}{c}\text { Maturity } \\
\text { Level }\end{array}$ \\
\hline Water & 3 & 0.70 & 2 & $1.25 \%$ & ML1 \\
Emissions & 1 & 0.80 & 1 & & \\
Energy & 4 & 0.60 & 3 & & \\
Materials & 13 & 0.48 & 4 & & \\
\hline
\end{tabular}

The results (Table 4) have shown that first the improvement's actions should be taken with regard to more responsible resource management for emissions ( $\left.\operatorname{Pr}_{\mathrm{EM}}=1\right)$, followed by water, energy, and materials. Then, the facility manager was asked to fulfill the RIO Matrix (Figure 5), which linked the operations in the remanufacturing process and assessment criteria. It took the facility manager about $20 \mathrm{~min}$ to perform this step. The traffic lights system was implemented for simplicity of the result's visualization, as a SME has limited human resources. The colors show the meaning as follows:

- Grey-not relevant for operations,

- green-low importance,

- $\quad$ orange-medium importance,

- red-high importance.

\begin{tabular}{|c|c|c|c|c|c|c|c|c|c|c|c|}
\hline No. & Operations & 离 & 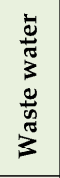 & U. & 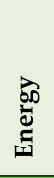 & 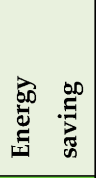 & 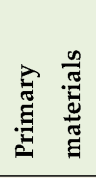 & 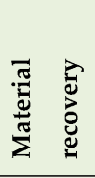 & 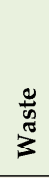 & 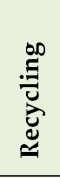 & 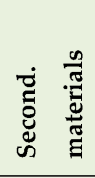 \\
\hline 1 & core delivery & & & & & & & & & & \\
\hline 2 & inspection & & & & & & & & & & \\
\hline 3 & disassembly & & & & & & & & & & \\
\hline 4 & induction & & & & & & & & & & \\
\hline 5 & $\begin{array}{l}\text { blasting } \\
\text { residue }\end{array}$ & & & & & & & & & & \\
\hline 6 & $\begin{array}{l}\text { material } \\
\text { consistency } \\
\text { test } \\
\end{array}$ & & & & & & & & & & \\
\hline 7 & \begin{tabular}{|l} 
differential \\
pressure test
\end{tabular} & & & & & & & & & & \\
\hline 8 & welding & & & & & & & & & & \\
\hline 9 & sanding & & & & & & & & & & \\
\hline 10 & painting & & & & & & & & & & \\
\hline 11 & re-assembly & & & & & & & & & & \\
\hline 12 & final testing & & & & & & & & & & \\
\hline
\end{tabular}

Figure 5. RIO (Resource's Importance in Operations) matrix for Company D.

The RIO matrix facilitated a quick scan of the remanufacturing process and identification of the hotspots, where the improvement's actions should be implemented first.

For example, (as indicated in Table 4) the category "Emissions" was given the priority $\operatorname{Pr}_{\text {EM }}=1$ (the highest). The Emissions (as indicated in RIO Matrix) were identified as medium important/important ("orange" and "red" areas) at operations: Residues blasting (cleaning), disassembly (as applied there cutting techniques have generated heat), and induction burning, welding, and painting. The transition towards higher maturity 
level should start by the management practice (RRMP) from next maturity level (ML2) for "Emissions":

$\mathrm{RRMP}_{\text {EmML2: }}$ GHG emissions are measured and monitored only if required by law, and legal requirements are fully implemented.

The first set of improvement actions should be directed to hotspots (orange and red areas from the RIO Matrix from Figure 5). The company could benefit from focusing on the limited area, without the need to monitor the whole process yet (as it is relevant to higher MLs). Therefore, the limitations of the SME (limited staff and financial resources) could be overcome. The proposed approach is iterative. After implementation of the proposed first set of improvements actions at operational level (residues blasting (cleaning), disassembly (as it involves cutting techniques which generate heat), induction burning, welding, and painting), the criterion value should be recalculated (see Table 5). The value of the indicator OWEEM should be recalculated in order to verify if the company has reached higher maturity level. As presented in Table 5, the company has improved the value of OWEEM, but it was not high enough to be classified as ML2. The second set of improvement actions should be focused on areas with the current highest priority, therefore in Company D the actions should be taken for the category "Water" $\left(a \operatorname{Pr}_{\mathrm{W}}=1\right)$. The transition towards higher maturity levels should be started by implementation of the management practices (RRMP) from ML2 for "Water". Category "Water" includes two criteria: "Water consumption level" and "Waste water".

Table 5. Transition towards higher maturity level ML2 in Company D.

\begin{tabular}{|c|c|c|c|c|c|}
\hline $\begin{array}{c}\text { Implementatio } \\
\text { 1st Set. }\end{array}$ & & & & & \\
\hline $\begin{array}{l}\text { Category } \\
\text { RG }_{\mathrm{Ci}}\end{array}$ & $\begin{array}{c}\text { RRMQ }_{\text {RGCi }} \text { Score } \\
\text { (Equation (3)) }\end{array}$ & $\begin{array}{c}\text { Maturity Gap } \\
\text { Mgap RGCi } \\
\text { (Equation (4)) }\end{array}$ & $\begin{array}{l}\text { Priority } \\
\operatorname{Pr}_{\text {RGCi }}\end{array}$ & $\begin{array}{c}\text { OWEEM } \\
\text { (Equation (1)) }\end{array}$ & $\begin{array}{c}\text { Maturity } \\
\text { Level }\end{array}$ \\
\hline Water & 3 & 0.70 & 1 & $2.50 \%$ & ML1 \\
\hline Emissions & 2 & 0.60 & 2 & & \\
\hline Energy & 4 & 0.60 & 2 & & \\
\hline Materials & 13 & 0.48 & 3 & & \\
\hline \multicolumn{6}{|c|}{$\begin{array}{l}\text { implementation of } \\
\text { 2nd set }\end{array}$} \\
\hline $\begin{array}{l}\text { Category } \\
\text { RG }_{\mathrm{Ci}}\end{array}$ & $\mathrm{RRMQ}_{\mathrm{RGCi}}$ Score & $\begin{array}{c}\text { Maturity Gap } \\
\text { Mgap }_{\text {RGCi }}\end{array}$ & $\begin{array}{l}\text { Priority } \\
\operatorname{Pr}_{\text {RGCi }}\end{array}$ & OWEEM & $\begin{array}{c}\text { Maturity } \\
\text { Level }\end{array}$ \\
\hline Water & 5 & 0.50 & 2 & $4.16 \%$ & ML2 \\
\hline Emissions & 2 & 0.60 & 1 & & \\
\hline Energy & 4 & 0.60 & 1 & & \\
\hline Materials & 13 & 0.48 & 3 & & \\
\hline
\end{tabular}

$\mathrm{RRMP}_{\text {WCML2 }}$ : Water usage is monitored ad hoc only at cost level (the invoices are reviewed), water is not reused.

RRMP $_{\text {WWML2: }}$ Sludge generation is monitored at cost level (reviewing invoices), water is not reused.

In the criterion "Waste Water", the company has already implemented the management practices RRMP ${ }_{\text {WWML2. }}$. Therefore, the focus should be placed now on application of

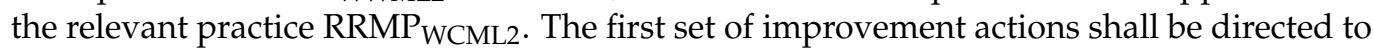
hotspots (orange and red area from RIO Matrix). In the RIO Matrix (Figure 5), the manager has not indicated hotspots for "Water use". In Company D, the existing technological process is not water-intensive. The water is used mainly for disassembly operations and in the general area (cleaning the facility, hygiene of employees). Nevertheless, the company should establish the awareness of the water usage, for that reason the implementation of the RRMP ${ }_{\mathrm{WCML} 2}$ has been recommended. The aggregated value (RRMQ $\left.\mathrm{RGCi}_{\mathrm{R}}\right)$ for the 
category "Water" has been recalculated (see Table 5), as well as the value of the OWEEM, and the company is classified at a higher maturity level (as ML2).

\section{Discussion and Managerial Implications}

The presented two-layered decision making framework allows for finding answers to the research questions:

- $\quad$ RQ1: How can the responsible resource management practices be evaluated in a SME based on the existing in-house expert's knowledge?

- $\quad$ RQ2: How can the current management practices be improved in order to facilitate transformation towards responsible resource management in a SME?

The previous studies $[14,33,34]$ have proven that remanufacturing SMEs struggle to achieve resource efficiency. The sophisticated quantitative tools are often not suitable for application at SMEs, as they don't have sufficient access to the external databases and software, due to high cost (of license's purchase) or work-load needed (limited employment and/or limited range of staff competences). Therefore, this paper presents a qualitative approach for assessment of the current practices with regard to responsible resource management. The testing in the SMEs has given positive feedback about the feasibility and applicability of the proposed framework. The first layer of the proposed framework is dedicated to the assessment of the current state, and thus it corresponds with the research question RQ1. The previous studies, e.g., [35,36] have highlighted benefits of remanufacturing for the environment from the product's perspective, but they have dedicated a very little attention to the responsible resource management in the remanufacturing process itself. The conducted case studies have confirmed that the application of the RRMQ is feasible, and it allows benefiting from the existing in-house expert's knowledge in a company. It provides insight on the existing management practices in a structured way.

The prescriptive layer of the RRMRem corresponds to the research question RQ2. The responsible management practices (RRMPs) are defined for each of the criterion, and then merged into categories: Water, Emissions, Energy, and Materials. In accordance with the taken "eco-efficiency" view, the responsible resource management practices (RRMPs) are designed to allow for reducing consumption of resources, reducing the impact on nature, and increasing the value of used resources. The analyzed criteria are related to remanufacturing process inputs (water, primary and secondary materials, energy consumption), outputs (emissions, sludge, process waste), and value added (energy saving, recycling, and increased material recovery). A similar approach has been recommended by Lundholm et al. [12].

The paper has got managerial implications, as the provided framework is designed taking in consideration the organizational conditions which exist in SMEs. RRMRem can support the decision-maker with guidelines on:

- Identifying in the synthetic way the current maturity level with usage of the RRMQ questionnaire, and then

- conducting in-depth analyses using RIO Matrix,

- $\quad$ prioritizing improvement's actions which should be taken first in order to move towards more resource responsible remanufacturing practices.

\section{Conclusions}

The proposed framework aims to guide the decision-makers towards more responsible resource management in the remanufacturing process in SMEs. It is designed to facilitate iterative and continuous transition in a company. The originality of this research results from relating (through maturity scoring) the current state of resource management in a company with the relevant management practices which shall be taken in order to progress to the higher maturity level. The paper contributes to the existing body of literature by extending the existing maturity models with a prescriptive layer. The two-layered structure of our framework allows for: 
- Maturity scoring;

- assessment of the maturity gap;

- prioritization of the required actions;

- design of the improvement's actions at the operational level; and

- continuous improvement by benchmarking with a higher maturity level.

The main benefit of the framework proposed here is its simplicity, and its accessibility. The testing in the remanufacturing sector has proven its suitability and feasibility for application in the organizational conditions, which are typical for SMEs. This pragmatic framework does not require collection of the extensive additional data or access to the external environmental databases. The framework utilizes the existing in-house expert's knowledge. Moreover, the structure of the framework is flexible, as the amount of criteria in each category can be extended or reduced in order to tailor it better to the existing conditions of remanufacturing process. For example, additional criterion can be added in the category "Emissions" if the remanufacturing technology used at a company is emission-intensive and various emissions should be considered separately.

The main limitation of this framework is that it has been elaborated based on the case studies, interviews with academia, and industrial experts only from the automotive sector.

Further research will include testing of the proposed framework in remanufacturing SMEs in different sectors in order to develop the sector-tailored catalog of the assessment criteria for the descriptive layer. Moreover, we will extend the propose framework by implementation of a decision tree for grouping criteria, and obtaining measurement spaces.

Supplementary Materials: The following are available online at https://www.mdpi.com/2079-9 276/10/2/19/s1, Table S1: RRMQ -Responsible resource management practices' questionnaire for remanufacturing SMEs.

Author Contributions: Conceptualization, P.G.-D.; methodology, P.G.-D. and K.W.-L.; validation, P.G.-D., K.W.-L. and M.K.-O.; formal analysis and investigation P.G.-D., K.W.-L. and M.K.-O.; writingoriginal draft preparation P.G.-D.; writing-review and editing, K.W.-L., M.K.-O.; visualization, P.G.-D., K.W.-L. and M.K.-O.; funding acquisition, P.G.-D., K.W.-L. and M.K.-O. All authors have read and agreed to the published version of the manuscript.

Funding: This research and the APC were funded by the grant of the Poznan University of Technology no. $11 / 140 /$ SBAD/4169.

Institutional Review Board Statement: Not applicable — this study did not require ethical approval. Informed Consent Statement: Not applicable.

Data Availability Statement: The data presented in this study are available on request from the corresponding author after prior approval from the participating companies.

Conflicts of Interest: The authors declare no conflict of interest. The funders had no role in the design of the study; in the collection, analyses, or interpretation of data; in the writing of the manuscript, or in the decision to publish the results.

\section{References}

1. Kjaer, L.L.; Pigosso, D.C.A.; Niero, M.; Bech, N.M. Product/Service-systems for a Circular Economy: The Route to Decoupling Economic Growth from Resource Consumption? J. Ind. Ecol. 2018, 23, 22-35. [CrossRef]

2. Tóth, G. Circular Economy and its Comparison with 14 Other Business Sustainability Movements. Resources 2019, 8, 159. [CrossRef]

3. Fogarassy, C.; Finger, D. Theoretical and Practical Approaches of Circular Economy for Business Models and Technological Solutions. Resources 2020, 9, 76. [CrossRef]

4. Schrettle, S.; Hinz, A.; Scherrer-Rathje, M.; Friedli, T. Turning sustainability into action: Explaining firms' sustainability efforts and their impact on firm performance. Int. J. Prod. Econ. 2014, 147, 73-84. [CrossRef]

5. Geissdoerfer, M.; Bocken, N.M.; Hultink, E.J. Design thinking to enhance the sustainable business modelling process-A workshop based on a value mapping process. J. Clean. Prod. 2016, 135, 1218-1232. [CrossRef]

6. Ellen Macarthur Foundation. Towards the Circular Economy: Accelerating the scale-up across global supply chains. In World Economic Forum Reports; 2014; Available online: https:/ / www.ellenmacarthurfoundation.org/publications/towards-the-circulareconomy-vol-3-accelerating-the-scale-up-across-global-supply-chains (accessed on 15 December 2020). 
7. Schaltegger, S.; Bennet, M.; Burritt, R.L.; Jasch, C. Environmental Management Accounting (EMA) as a Support for Cleaner Production. In Environmental Management Accounting for Cleaner Production; Springer: Dordrecht, The Netherlands, 2009; Volume 24, pp. 3-26. [CrossRef]

8. Lieder, M.; Rashid, A. Towards circular economy implementation: A comprehensive review in context of manufacturing industry. J. Clean. Prod. 2016, 115, 36-51. [CrossRef]

9. Rashid, A.; Asif, F.M.; Krajnik, P.; Nicolescu, C.M. Resource conservative manufacturing: An essential change in business and technology paradigm for sustainable manufacturing. J. Clean. Prod. 2013, 57, 166-177. [CrossRef]

10. Mancini, L.; Nuss, P. Responsible Materials Management for a Resource-Efficient and Low-Carbon Society. Resources 2020, 9, 68. [CrossRef]

11. Statista 2020. Available online: https://www.statista.com/statistics/878412/number-of-smes-in-europe-by-size/ (accessed on 15 December 2020).

12. Lundholm, T.; Lieder, M.; Rumpel, G. Resource Efficiency Assessment System. Leveraging Technology for a Sustainable World. In Proceedings of the 19th CIRP Conference on Life Cycle Engineering, University of California at Berkeley, Berkeley, CA, USA, 23-25 May 2012; pp. 423-428. [CrossRef]

13. Golinska, P.; Kosacka, M.; Mierzwiak, R.; Werner-Lewandowska, K. Grey Decision Making as a Tool for the Classification of the Sustainability Level of Remanufacturing Companies. J. Clean. Prod. 2015, 105, 28-40. [CrossRef]

14. Golinska-Dawson, P.; Kuebler, F. Sustainability Assessment in Remanufacturing Companies-Qualitative Approach. In Sustainability in Remanufacturing Operations; EcoProduction; Springer International Publishing: Cham, Switzerland, 2018 ; pp. 79-91. [CrossRef]

15. Golinska-Dawson, P. Decision making framework enabling sustainable remanufacturing in small and medium sized enterprises in the automotive sector. In Proceedings of the 35th International Business Information Management Association Conference (IBIMA), Seville, Spain, 1-2 April 2020.

16. Garengo, P.; Biazzo, S.; Bititci, U. Performance measurement systems in SMEs: A review for a research agenda. Int. J. Manag. Rev. 2005, 7, 25-47. [CrossRef]

17. Golinska-Dawson, P. Sustainability in remanufacturing process-The challenges for its assessment. In Sustainability in Remanufacturing Operations; Springer International Publishing: Cham, Switzerland, 2018; pp. 1-12. [CrossRef]

18. Gutowski, T.; Sahni, S.; Graves, S.C. Remanufacturing and Energy Savings. Environ. Sci. Technol. 2011, 45, 4540-4547. [CrossRef]

19. Yan, W.; Chai, J.; Qian, Z.; Tsai, S.-B.; Chen, H.; Xiong, Y. Operational Decisions on Remanufacturing Outsourcing Involved with Corporate Environmental and Social Responsibility-A Sustainable Perspective. Sustainability 2018, 10, 1132. [CrossRef]

20. Matsumoto, M.; Chinen, K.; Endo, H. Paving the Way for Sustainable Remanufacturing in Southeast Asia: An Analysis of Auto Parts Markets. J. Clean. Prod. 2018, 205, 1029-1041. [CrossRef]

21. Golinska, P.; Kuebler, F. The Method for Assessment of the Sustainability Maturity in Remanufacturing Companies. Procedia CIRP 2013, 15, 201-206. [CrossRef]

22. Correia, E.; Carvalho, H.; Azevedo, S.G.; Govindan, K. Maturity Models in Supply Chain Sustainability: A Systematic Literature Review. Sustainability 2017, 9, 64. [CrossRef]

23. Machado, C.G.; de Lima, E.P.; da Costa, S.E.G.; Angelis, J.J.; Mattioda, R.A. Framing maturity based on sustainable operations management principles. Int. J. Prod. Econ. 2017, 190, 3-21. [CrossRef]

24. Bititci, U.S.; Garengo, P.; Ates, A.; Nudurupati, S.S. Value of Maturity Models in Performance Measurement. Int. J. Prod. Res. 2015, 53, 3062-3085. [CrossRef]

25. Pullen, W. A Public Sector HPT Maturity Model. Perform. Improv. 2007, 46, 9-15. [CrossRef]

26. Veleva, V.; Hart, M.; Greiner, T.; Crumbley, C. Indicators of Sustainable Production. J. Clean. Prod. 2001, 9, 447-452. [CrossRef]

27. Lewis, M.; Brandon-Jones, A.; Slack, N.; Howard, M. Competing through Operations and Supply: The Role of Classic and Extended Resource-Based Advantage. Int. J. Oper. Prod. Manag. 2010, 30, 1032-1058. [CrossRef]

28. Pigosso, D.C.A.; Rozenfeld, H.; McAloone, T.C. Ecodesign Maturity Model: A Management Framework to Support Ecodesign Implementation into Manufacturing Companies. J. Clean. Prod. 2013, 59, 160-173. [CrossRef]

29. Butzer, S.; Schötz, S.; Steinhilper, R. Remanufacturing Process Capability Maturity Model. Manufacturing 2017, 8, 715-722. [CrossRef]

30. Röglinger, M.; Pöppelbuß, J.; Becker, J. Maturity Models in Business Process Management. Bus. Process Manag. J. 2012, 18, 328-346. [CrossRef]

31. Tarhan, A.; Turetken, O.; Reijers, H.A. Business Process Maturity Models: A Systematic Literature Review. Inf. Softw. Technol. 2016, 75, 122-134. [CrossRef]

32. Kleindorfer, P.R.; Singhal, K.; Van Wassenhove, L.N. Sustainable Operations Management. Prod. Oper. Manag. 2005, 14, 482-492. [CrossRef]

33. Kurilova-Palisaitiene, J.; Sundin, E.; Poksinska, B. Remanufacturing Challenges and Possible Lean Improvements. J. Clean. Prod. 2018, 172, 3225-3236. [CrossRef]

34. Matsumoto, M.; Yang, S.; Martinsen, K.; Kainuma, Y. Trends and research challenges in remanufacturing. Int. J. Precis. Eng. Manuf.-Green Technol. 2016, 3, 129-142. [CrossRef] 
35. Schau, E.M.; Traverso, M.; Finkbeiner, M. Life Cycle Approach to Sustainability Assessment: A Case Study of Remanufactured Alternators. J. Remanuf. 2012, 2, 1-14. [CrossRef]

36. Warsen, J.; Laumer, M.; Momberg, W. Comparative life cycle assessment of remanufacturing and new manufacturing of a manual transmission. In Glocalized Solutions for Sustainability in Manufacturing; Springer: Berlin/Heidelberg, Germany, 2011 ; pp. 67-72. [CrossRef] 